\title{
Leadership, Service Learning, and Executive Management in Engineering: The Rowan University Hurricane Katrina Recovery Team
}

\author{
Jacqueline Finger ${ }^{1}$ \\ Electrical and Computer Engineering \\ Senior Manager and Team Leader \\ Joseph Lopez, III \\ Electrical and Computer Engineering \\ Senior Manager and Team Leader \\ Christopher Baralus \\ Civil Engineering \\ Team Leader \\ Matthew Parisi \\ Civil Engineering \\ Team Leader \\ Fred Rohs \\ Mechanical Engineering \\ Team Leader
}

John Schmalzel

Professor, Electrical and Computer Engineering

Faculty/Project Advisor

Amrinder Kaur

Educational Leadership

Graduate Advisor and

Service-Learning Coordinator
DeMond S. Miller*

Associate Professor, Sociology

Faculty Project Advisor

Primary Contact

millerd@rowan.edu

Kimberly Reese

Center for Student Leadership and Service

Xavier University of Louisiana

Abstract - The Rowan University Hurricane Katrina Recovery Team Project is a service learning endeavor undertaken by students and faculty in various disciplines at Rowan University. The objectives of this service learning endeavor are threefold. The main objective is to help distressed communities in the Gulf Coast Region. Second, this project seeks to not only address broader social issues but to also leave a tangible contribution or impact in the area while asking the following questions: what do we as professional engineers have as a responsibility to the communities we serve, and what do we leave in the community to make it a better, more equitable place to live? The last objective is the management team's successful assessment of the experience, including several logistical challenges. To this end, this article seeks to help other student-led projects by relaying our service learning experience in a coherent, user-friendly manner that serves as a model experience. By offering peer-to-peer advice in service learning, we wish to break down 
apprehension about service-learning opportunities and serve as a catalyst for other such endeavors. First, this paper will cover the importance of such endeavors as well as the methods and organizational skills used to design a project. Next, it will illustrate the type of work that was completed in an effort to help rebuild the New Orleans area. Finally, it will offer advice and recommendations for other students organizing similar projects by evaluating a multi-team project approach.

Index Terms - Katrina, project management, social needs

\section{INTRODUCTION}

Each semester, students from Rowan University's Engineering program form collaborative teams and engage in "hands-on" projects beyond the standard classroom education experience. This opportunity is known as the Engineering Clinic ${ }^{2}$ at Rowan University and is taken by all engineering students as part of an eight-semester course sequence. Clinic projects span the range of engineering disciplines offered at Rowan University; the clinic experience is designed to aid in the development and use of necessary skills in the field of engineering. ${ }^{3}$ Once students reach their Junior and Senior years, they are given various choices for their clinic experiences, which include prospects such as industry-sponsored or government-funded research, entrepreneurial opportunities, and service learning projects.

The Hurricane Katrina Recovery Project was created to give students the opportunity to organize, develop, and execute a student-led service initiative. Since Hurricane Katrina hit the New Orleans area in 2005, clinic teams have been engaging in a variety of projects in conjunction with other volunteers in the New Orleans area. For two years, multidisciplinary teams of over 125 students and faculty members from all disciplines at Rowan University have collaborated and worked under the leadership of an engineering clinic team. This type of clinic experience infuses service learning into the curricular offerings while exposing engineering students to the demands of managing a multidisciplinary work environment. The management of work teams is a powerful skill needed in the workplace. The responsibilities of clinic team managers ${ }^{4}$ included organizing and executing the trips for volunteers. These responsibilities help the student senior managers and team leaders understand aspects of project management, organization, operations logistics, budgeting, and working with colleagues and administration.

The Hurricane Katrina Recovery Project incorporated a variety of fundamental skills that are essential to everyday engineering practices. Project management is perhaps the most important and challenging component for the leadership team. For large scale activities, it is crucial to be able to organize, control, and prepare for a multitude of contingencies that arise during the course of a project. ${ }^{5}$ Leadership qualities, such as good communication, organization, dedication, problem solving, and team motivation, are important for team leaders; these qualities help ensure the smooth operation of the daily activities of the seven to ten member smaller groups and for the general welfare of the larger group. Another key responsibility included communicating and networking with various resources (both local and distant) to establish contacts and deadlines for any goods and services needed during the trip. However, budgeting and time management were the most critical, and the most variable, components of the project.

Preparation is crucial for a project of this magnitude. For the project to run in an organized and controlled manner, many steps were taken months in advance to anticipate diverse situations. The goal for the Spring 2007 semester was to open the project to the entire campus and to 
include as many as forty-five students and five faculty members. This goal seemed to be reasonable due to past efforts of the relief group. Among these volunteers, there was a group of five student leaders who were ultimately responsible for the project logistics. The management team consisted of the student leaders, faculty advisors, and a graduate student. Finally, the volunteers consisted of students from throughout the University with varied backgrounds. These participants engaged in fundraising activities and prepared for travel to New Orleans, Louisiana, during Rowan University's spring break week (March 11-17).

Because accommodations for a week are important, the management team consulted a variety of service options early in the project's selection to economically accommodate large groups. Among these options were Habitat for Humanity International, The National Relief Network, Break Away, and even other universities, such as the University of Washington, and Xavier University of Louisiana (XULA). It was determined that the best option would be to coordinate an effort with XULA's existing program. XULA is a historically Catholic and Black university located in New Orleans. Founded in 1925 by Saint Katharine Drexel, the university's ultimate purpose is the promotion of a more just and humane society. To this end, XULA prepares its students to assume leadership and service roles in society. This preparation takes place in a pluralistic teaching and learning environment that incorporates all relevant educational means, including research and community service. Each decision was made as a team after a thorough investigation of the possible outcomes and their ability to help achieve our main objectives.

In the fall of 2005, XULA was forced to suspend classes indefinitely when Katrina's storm surge ripped through the city and the breeches in the levee system caused 80 percent of the city to flood. XULA received approximately $\$ 30$ million for wind and water damage. In September, after assessing the damage and reiterating Xavier's commitment to education, Dr. Norman C. Francis, President of XULA, informed students, faculty, and staff that the university would reopen in January 2006. Dr. Francis also challenged the Center for Student Leadership and Service to enhance its services to the community and transform the service projects facilitated pre-Katrina to meet the needs of the city and community post-Katrina. The Center for Student Leadership and Service is designed to promote student management and civic engagement by complementing the academic curriculum with practical application of classroom theory and methodology.

A major initiative of the Center for Student Leadership and Service was facilitating alternative break programs for colleges and nonprofit organizations desiring to assist New Orleans and the Gulf Coast in reconstruction. A major challenge for many groups is securing appropriate housing and community service sites while residing in cities hours away from New Orleans. With funding assistance from the Corporation for National and Community Service's Learn and Serve Division, the Center for Student Leadership and Service designated a residence hall that was vacant due to decreased enrollment to house volunteers. Additional local resources were provided, such as secured vans, a van driver, and community site liaisons, to assist with logistics and ensure a meaningful service project. The Center for Student Leadership and Service also hosted a half-day orientation session designed to provide information about the city of New Orleans, both before and after Katrina, and to relate stories of some affected residents to student volunteers. 


\section{Social NeEds, Community, ANd Curriculum}

Because the long-term implications of Hurricane Katrina will remain for years to come, a fullfledge, well-sustained commitment to the rebuilding efforts is required for rebuilding. To meet this need, the American people responded to the Gulf Coast area in an unprecedented manner. Communities sent equipment, food, supplies, and opened their homes to the survivors of this tragedy. Moreover, universities have come to the aid of displaced students and faculty in a variety of ways in the immediate aftermath of the disaster. ${ }^{6}$ However, in the post-impact phase of the disaster, and in an attempt to aid the region's long-term recovery process, hundreds of volunteer groups entered New Orleans in a variety of efforts as individuals, Alternative Spring Break Activity groups, and service learning organizations. Many of the activities included supply distributions, providing basic health care, pre-trip fundraising, tutoring, and environmental testing. The most common tasks - and where Rowan University's team focused its work over the past two years-have been in housing and building restoration.

The common engineering clinic sequence is designed to help students meet the Accreditation Board for Engineering and Technology's (ABET) criteria (a) through (k). ${ }^{7}$

... students [participate] in teams, often interdisciplinary, working on hands-on activities, report writing and presentations. In the final four semesters of a student's career, the Clinics change from somewhat structured and common for all the students in the same course or section to semester or year-long, open-ended design projects and the inclusion of both Junior- and Senior-level students into typically 3-6 member teams. The idea of a project or projects related to hurricane recovery efforts would fit well in the context of the Junior/Senior Clinic and offer the students the opportunity to engage in service learning activities of addressing community needs, student learning, reciprocity and reflection. ${ }^{8}$

In addition to the Engineering Clinic offering an alternative learning environment, it helps meet many of the Rowan University program goals. More specifically, the Clinic students engage in projects that enable them to be agile problem solvers, making them adaptable to new situations in which they can be effective communicators and meet the needs of the ever-changing environment of daily team logistics in a project nearly 2,000 miles away from their base. Also, as a part of this service learning experience, they are able to link their volunteer experiences to realworld business and entrepreneurial opportunities. Students learn and exchange ideas with engineers and other professionals onsite to integrate knowledge and skill sets to accomplish given tasks. Finally, such a learning environment is valuable in the sense that the "clinical" or "experimental" atmosphere of the classroom is removed and the open-ended project must incorporate the natural environment. This sensitizes students to the real-world socio-economic, political, and ethic/cultural effects of their service on various social classes. ${ }^{9}$ Service learning offers pedagogical and experiential approaches to breaching these divides through intentionalreflective learning that connects disciplinary content to societal challenges. ${ }^{10}$

Due to the service learning orientation of the initiative, the leadership team and the student volunteers were exposed to several lectures on culture, opportunities to reflect orally and in written form on their activities, trips to museums, interviews with survivors of Hurricane Katrina, and experiences with the culture that defines New Orleans as a distinct place with a unique ethnic make up. The experience is valuable because it forced students to employ local knowledge about climate topography and new building codes in relation to what they already 
know about engineering principles. We believe that a clinic of this magnitude provides a comprehensive immersion into an environment that tested the resolve to get the projects done and required participants to reflect on the service's societal effect on the city and region within a multidisciplinary context.

\section{The ReCOVERY Clinic EXPERIENCE}

The forty-six volunteers worked at seven project sites in New Orleans. The worksites were located in the Historic Seventh Ward, Eastern New Orleans, Gentilly, and the Lower Ninth Ward. The large group was broken into five smaller groups, each with eight to ten people led by a management team.

A typical day for the student volunteers consisted of a work period, meals, and planned activities or free time. Each day began at 7:30 A.M. with breakfast from the cafeteria located on XULA's campus. The five teams prepared for the workday by packing their tools, safety gear, water, and other supplies in the vehicles that would transport them to their worksite. After an approved inspection of the individual worksites by the faculty leader and management team members, the local site coordinator delegated tasks among the teams; the team leaders then divided the volunteers and had them perform specific job-related tasks. At 12:30 P.M., lunch was delivered by a community volunteer. Throughout the workday, the students were free to take water breaks and encouraged to remain hydrated. Work continued until 3:00 P.M. to allow enough time for site clean up and to give ample time for all work teams to return to campus, shower, and prepare for dinner at 5:00 P.M. After dinner, everyone would meet for a common team and service learning reflection meeting. Between the evening team meeting and lights out, the team participated in either a scheduled activity or were given free time. ${ }^{11}$

The projects were divided among the teams. At the beginning of the week, each of the five subgroups had a specific project, but as with any project, minor deviations occurred. On some occasions, sites were not cleared properly, the tools required were not available, or projects were completed prior to the projected completion times. The students' schedules were flexible, which allowed them to accomplish several tasks at several sites. In each case, the management team and volunteers worked together and successfully resolved problems without much difficulty. The management team only had a week to start and complete projects, so they had to strategically plan their resources for the week. This was achieved through months of preparation, clear communication, and the cooperation of the student volunteers.

Project site \#1 was house gutting and demolition. Their assigned house was located in the Historic Seventh Ward on North Johnson Street, New Orleans. Each day of the project, there were at least ten workers and up to eighteen workers on a given day. The job began with clearing the house of all debris and furniture, which was followed by demolition of the walls and ceiling, removal of the bathtub, removal of nails and screws from studs, removal of wall debris, demolition of a backyard shed, removal of shed debris, and site clean-up. This project began on Monday and was completely finished by Friday. 


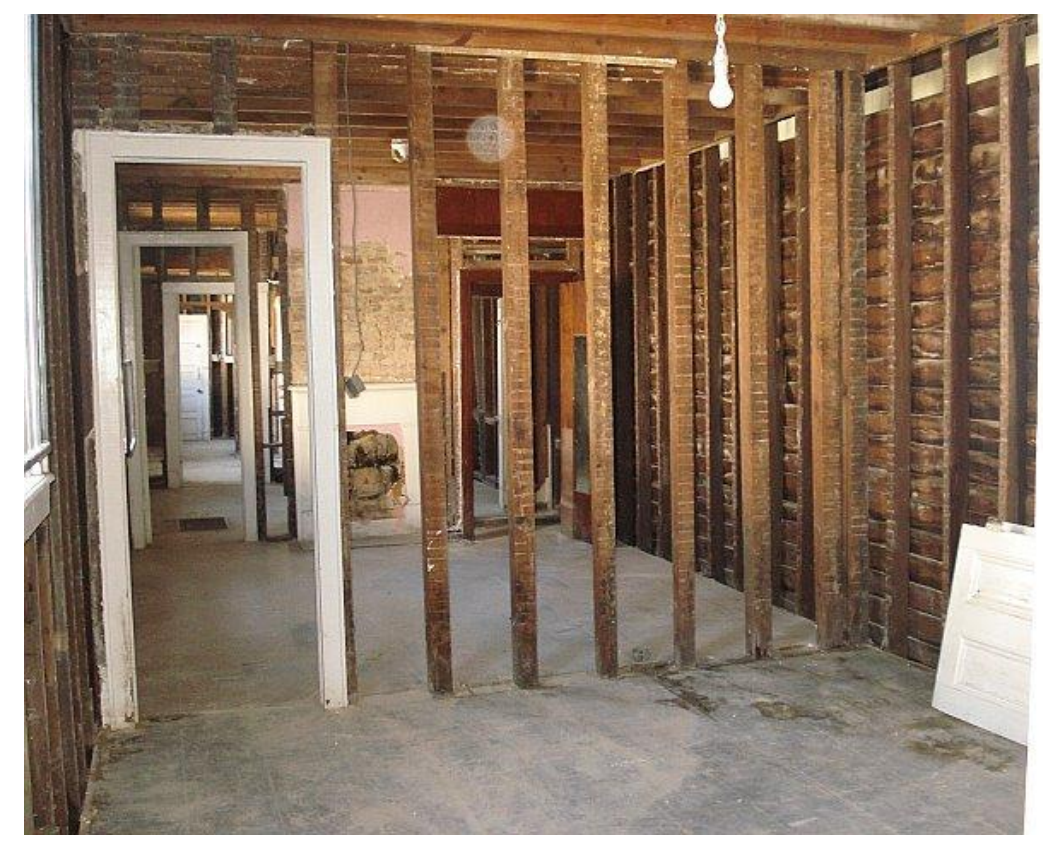

FIGURE 1

COMPLETE Project Site AT N. JOHNSON STREeT

Project site \#2 was a house on the corner of A. P. Tureaud and Duels Street, New Orleans. The team hung dry wall after gutting one room. Overall, this team had ten faculty and student volunteers. Drywall panels were first hung in the two front rooms of the house, then ceiling drywall was installed; next, two other rooms were gutted, then dry wall was installed in the remaining four rooms. This was the order of actions taken as the goals of the project site changed.

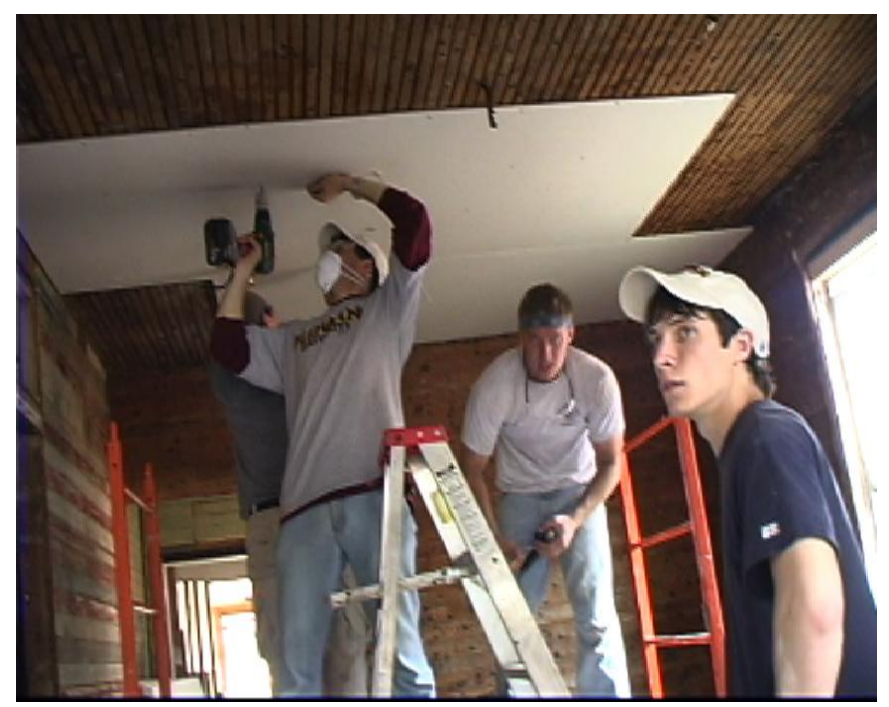

FIGURE 2

STUDENT VOLUNTEERS PUTTING UP DRY WALL FOR A CEILING AT PROJECT SITE 2 
Project site \#3, located at Prince Street, New Orleans, included general cleaning of the house and painting of the second floor. This project was completed with nine team members within the allotted timeframe. The first task involved removing damaged furniture, carpeting, and other debris from the house. The backyard was also cleaned by debris removal. The upstairs of the house did not have as much damage as the downstairs, so it was simply painted. Each task took approximately one day to complete. As the job neared completion, half the group was reassigned to debris removal at project site \#2. Another small subgroup helped install toilets and clean debris from a house.

Project site \#4 was another house on Duels Street. Here, a team of nine students worked around the house performing tasks such as sanding, caulking, and glazing windows and sanding lawn chairs. This smaller project took approximately two and a half days to complete. This group was reassigned after completion of their project to gut a house.

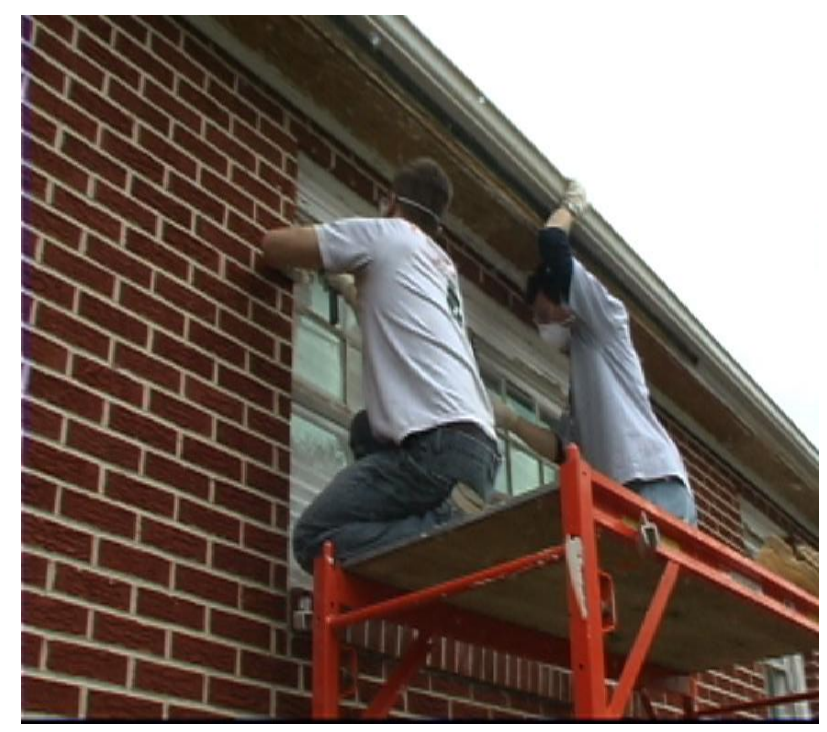

FIGURE 3

STUDENT VOLUNTEERS SANDING WINDOWS

Project site \#5 started as yard cleaning that seemed like a minor job until the team arrived at the site. The grass and weeds had grown above a person's knees. In the back of the house, the shed had collapsed and debris was scattered. This site had ten volunteer workers who were divided into smaller tasks to work more efficiently. The yard was weeded, the grass was cut, debris was removed, the backyard shed was demolished, and small trees were removed. Once the job was complete, the yard was neat, presentable, and ready for the homeowner to begin the reconstruction process. 


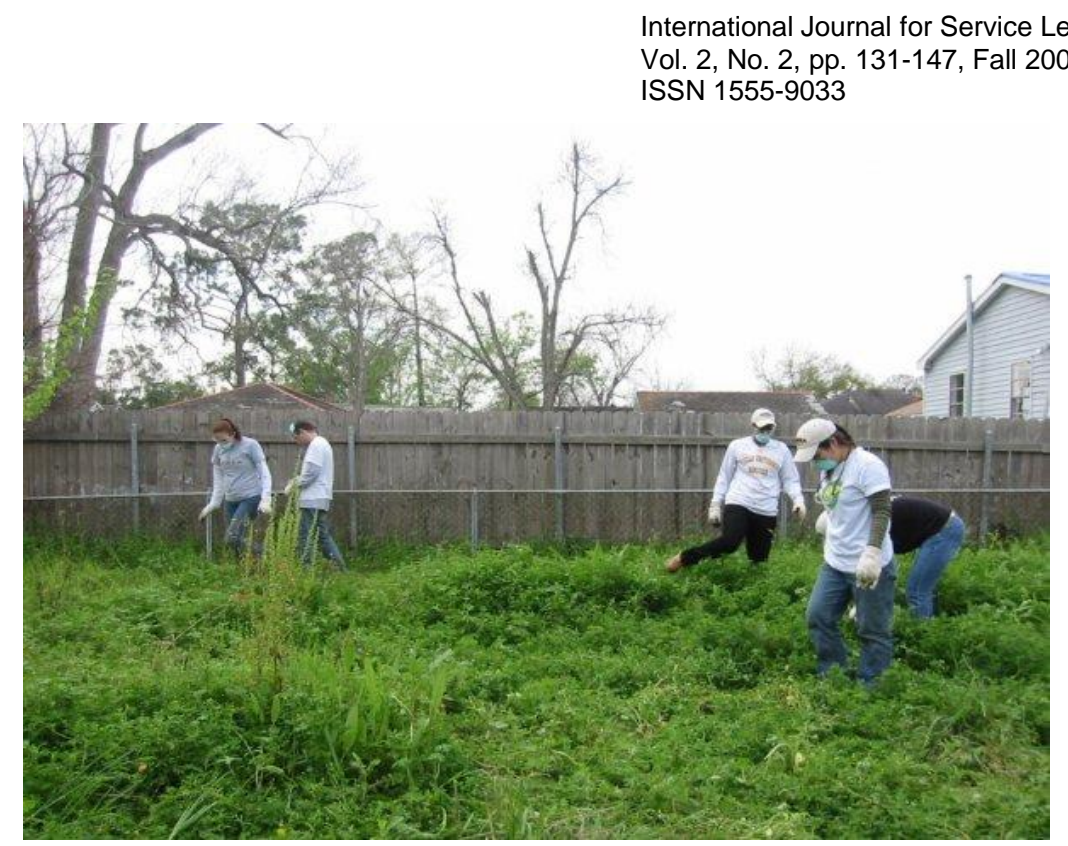

FIGURE 4

STUDENT VOLUNTEERS CLEARING DEBRIS FROM A BACKYARD AT PROJECT SITE 5

Once the original five projects were finished, a few of the teams continued working on other sites, such as moving furniture at the historic restaurant, Dookey Chase's, and gutting a house on Flood Street. Two other locations involved yard clean-up, debris removal, and toilet installation. Overall, the five teams were assigned to a total of nine different locations, completing tasks members of the community deemed valuable.

At the conclusion of each day, meetings were held among the team management to allow time for concerns to be addressed. Reflection meetings were also held with both team management and student workers present. Students would report on the status of their project site, describe how their day went, and voice their thoughts and opinions on the cultural, political, structural, and work-related issues in New Orleans. This gave everyone an opportunity to express feelings and propose solutions.

Reflection is an integral part of the learning cycle; reflection allows us to evaluate a particular experience, identify our strengths and weaknesses, and formulate and implement new ideas. ${ }^{12}$ Many of the outcomes associated with reflective service-learning, such as a sense of personal efficacy and other elements of personal and social commitment, have been linked to increased community involvement. ${ }^{13}$ In service-learning, reflection promotes a deeper-level interpretation of the experience, which leads to added meaning to services provided; knowledge and deep understanding come through a process of constructing knowledge through assessment of experience. ${ }^{14}$ During this trip, special consideration was given to the time allotted for reflection. At the end of each workday, students and the management team participated in a reflection session where they shared the "highs" and "lows" of their day. Furthermore, students were encouraged to share their experiences and express their feelings freely with the entire group. A final, structured reflection session was held at the conclusion of the trip to bring closure to the weeklong journey. These reflection sessions provided students with the opportunity to critically examine the services they provided and understand its effect on the larger community. 


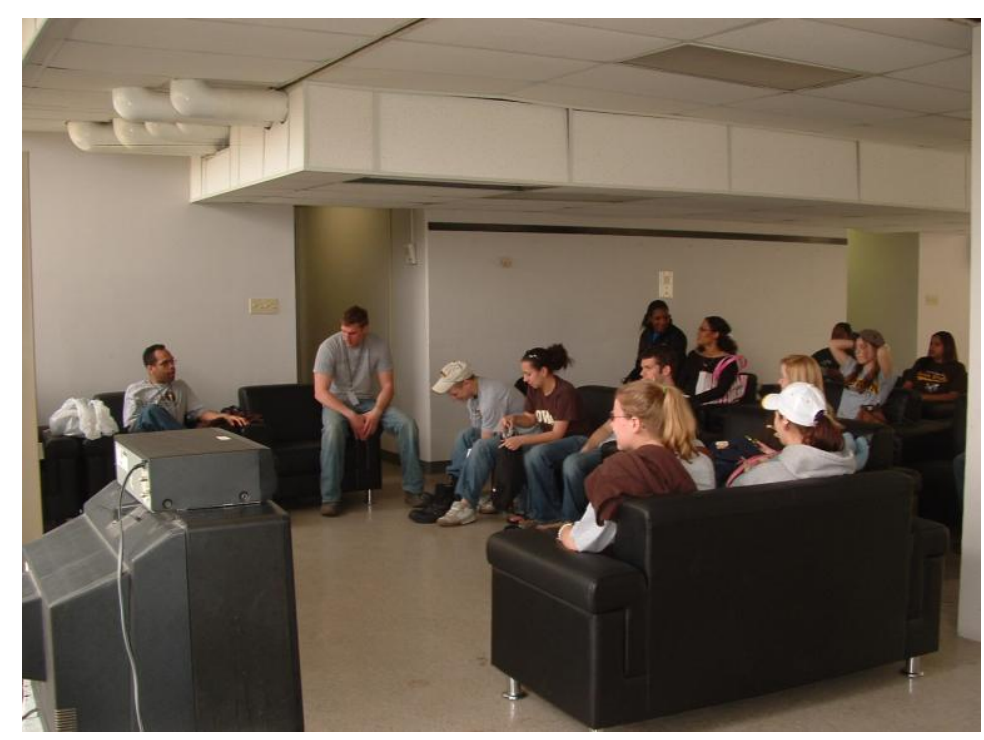

FIGURE 5

REFLECTION MEETING BACK AT XULA

\section{ENGINEERING MANAGEMENT AND LEADERSHIP SKILLS}

Leadership roles allowed the management team to effectively communicate, motivate, and direct individual student volunteers to collaborate to accomplish goals throughout the entire scope of the project. It also provided an avenue for students to take charge of finding resources and networks that may be beneficial to the success of the project. These qualities become useful in preparing students to handle unexpected situations in a calm, organized, and professional manner. ${ }^{15}$ The senior managers' team took on the dominant role within the project regarding the evaluation, progress, and responsibilities of the larger team.

\section{Tasks Associated with Project Management}

Numerous tasks are associated with project management, including communication, budgeting, logistics, and time management. ${ }^{16}$ No component of this project was independent, which is why the management process was so important for the outcome of the trip. From the project's inception, communication played a key role. Management meetings and teleconferences were held regularly during the trip and continued after its completion. Communication also provided an opportunity for a steady evaluation of the project's goals and the delegation of responsibilities from the its onset through its completion.

After researching possible sites at which to base the service project, communication was initiated with XULA. Extensive talks regarding lodging the volunteering students and providing other accommodations such as dining and cleaning facilities took place between the management team and XULA's Department of Student Affairs. After the accommodations for housing and dining were confirmed amongst the aforementioned parties, campus-wide announcements were sent through e-mail, and posted signs informed the students of the details of participating in this 
venture. Interest meetings were scheduled to bring awareness to the students seeking an alternative spring break experience.

Students were selected via an application process created by the student leaders to incorporate a diverse group of volunteers. Diversity, in the management team's opinion, would be ensured by selecting students with different ethnic backgrounds, cultural interests, programs of study, and ages. The management team felt that a group selected based upon these criteria would create an environment in which the volunteers could learn not only from their surroundings but from the life experiences of one another. Upon selection, weekly team meetings were scheduled to discuss the service learning components and other logistic details.

Management team research on transporting a large group to the worksite revealed that commercial air travel was the most economic and safe method of travel. In order for the group to travel locally around New Orleans, commercial vans were rented. This transportation was cheaper and more effective when compared to busing. With local transportation at hand, planned events were coordinated to allow students the opportunity to experience the art, history, and culture of the area without interfering with the main goals of the project. Moreover, the studentled management team was clear to communicate the project's budget and cost analysis to faculty advisors and student volunteer groups as they related to the logistical aspects of the project. Without sufficient funding, logistical options become increasingly limited. Fundraising in conjunction with the Rowan University Foundation began early to help offset project costs. Sponsor forms and donations were the main sources of funding, but food sales, several local businesses, and food chains also contributed to the overall fundraising effort.

\section{MANAGEMENT IN THE FIELD}

The true "on-site" management experience occurred during the actual trip. In this setting, the management team was constantly faced with situations that required quick thinking, problem solving, and "real-time" management skills. Accountability became a major concern because leaders were actively working and planning to ensure the project remained on schedule and within budget while embracing the ever-changing conditions of the workplace. At the same time, leaders were deciding on an effective form of resource allocation to complete each task. Outside of the worksites, the individual team leaders were in constant communication with one another, whether through formal team meetings or by general conversation. For a group of nearly fifty individuals, simple tasks such as eating and showering are complex when taking into account time management and deadlines. Preparation was an invaluable tool because these complications extend to all aspects of the "real-time" management experience, including logistics, budgetary concerns, communications, and time management.

\section{Evaluating The MANAgement EXPERIEnCE}

Projects, as open systems, and the team's performance were evaluated as an ongoing process by measuring the goals and objectives of the projects and utilizing feedback to determine how well the projects were doing and if they should be altered. ${ }^{17}$ The team obligated itself to reflect and reevaluate its performance on a regular basis through progress updates and team meetings. Established project management goals were analyzed to determine whether further action was 
necessary or sufficient progress was being made to continue. Peer evaluation was made by both the students involved and the faculty advisors overseeing the projects. Evaluation occurred before, during, and after each project had been completed.

\section{STUDENT BENEFITS}

Sometimes students in institutions of higher learning become detached from the outside world as they engage in academic activities. Specifically, service learning challenges traditional ways of teaching by replacing detachment with connectedness. ${ }^{18}$ Service learning is a way to tie academic lessons with a needed service. ${ }^{19}$ Whether the opportunity takes place in the same community as the school or across the country, the experience helps participants gain valuable skills and expertise. ${ }^{20}$ The spring 2007 Katrina Relief Trip stands as a solid example of how service learning can help cultivate students into productive members of society.

Service learning provides a key outlet for college students to get involved with the community. By traveling to New Orleans, students were able to get a perspective on a different culture. While working in the city to rebuild, a greater sense of the lifestyle that was a staple of the city could be observed. It was almost as if members of an entire city knew one another by name. Students were able to sense the feeling of community that the whole city shared. This feeling of community, coupled with the hospitality of what seemed like every person met contributed to a unique and overall fulfilling experience.

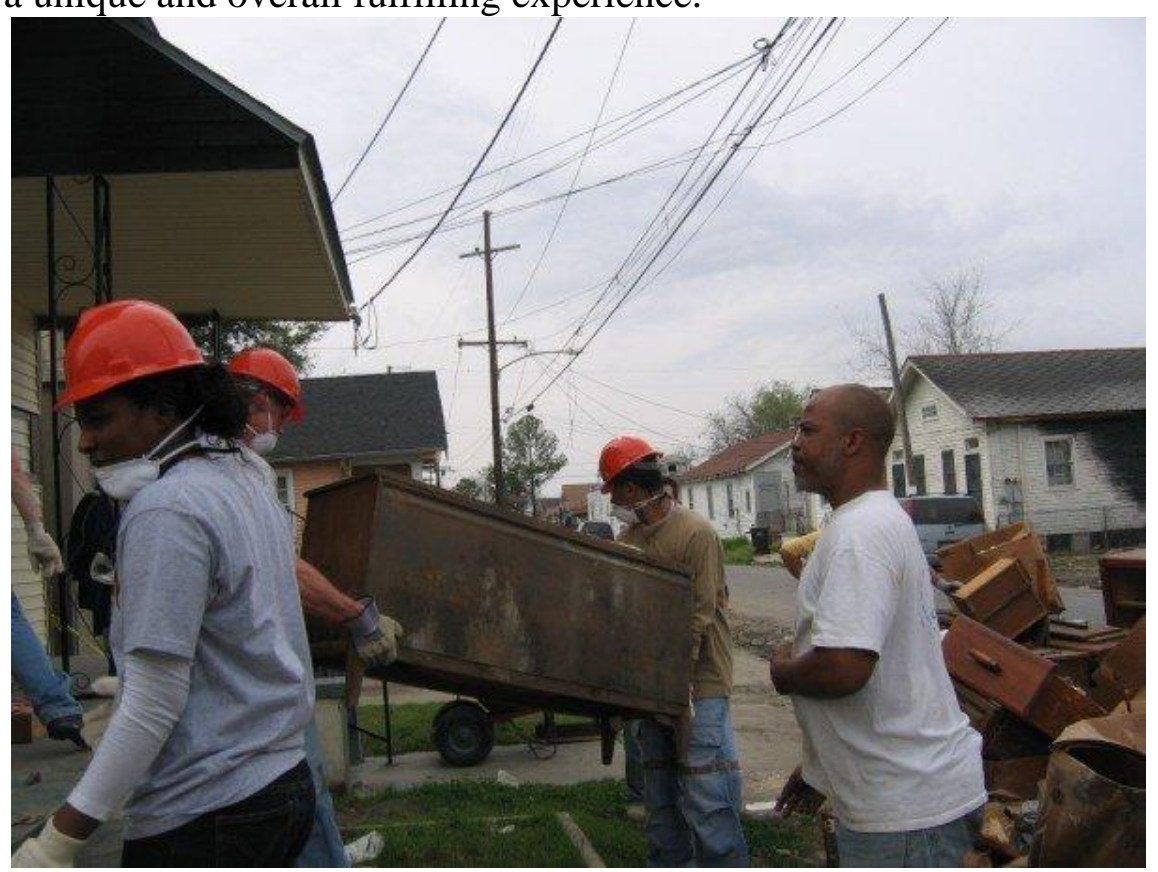

FIGURE 6

STUDENTS WORKING TOGETHER TO REMOVE DEBRIS FROM A HOUSE

A service learning experience is also an opportunity for students to build the work force skills they will need for the future. Teamwork and communication are important tools used 
during a service learning experience. Students with little to no prior experience learn to accommodate different styles of doing things while working in a structured environment, possibly for the first time. It is also a good learning experience for students who may not have had the opportunity to learn certain skills before. Sanding, painting, hanging drywall, and house gutting are all tasks in which students participated during the 2007 The Hurricane Katrina Recovery Team Project. While all of the student volunteers participated in these low-skill tasks, the management team engaged in a very detailed engineering project. Identifying the tasks at hand, acquiring the personnel to perform the tasks, funding the venture, and then executing the entire plan in a disaster-stricken area were extreme engineering management problems.

The drywall project provided evidence of how much certain students learned. The drywall team began the first day at a very slow pace and barely made any progress. However, with help from professors and experienced students, members of the team learned how to properly hang a panel of drywall, secure it, tape and plaster, and sand it to a finish. The project was soon moving at a rapid pace to complete the task on time and within budget. During reflection sessions after the workday, students commented on their abilities. For example, one woman who was working on the house-gutting project mentioned how she would never had thought herself capable of knocking down a wall, but by the end of the day, she had done this and more. The Katrina Relief Trip gave students the opportunity to walk away from the project with a new set of skills.

\section{COMMUNitY BENEFITS}

Service learning provides communities the opportunity to take advantage of valuable time and labor for which someone would otherwise have to pay. This may seem unethical in that local businesses or ventures are being outsourced for this type of labor; however, in communities

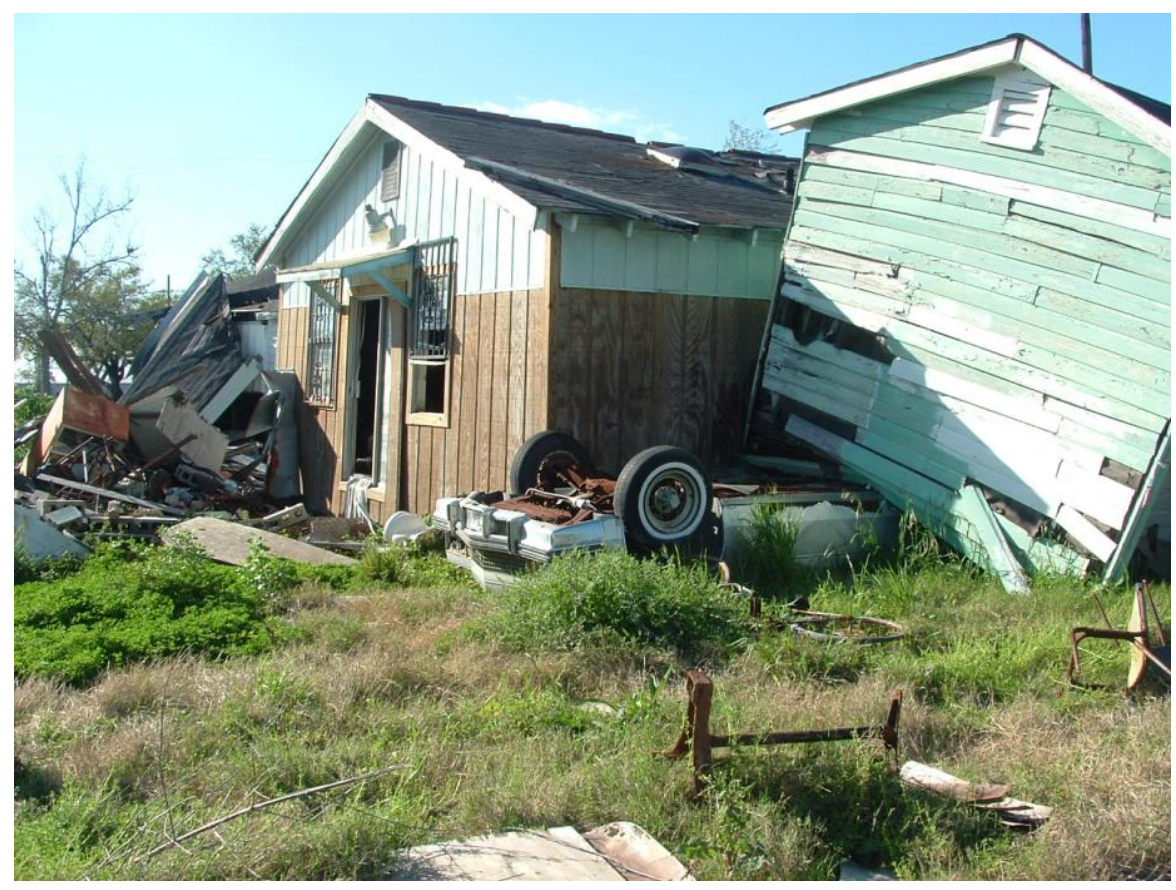

FIGURE 7 stricken by poverty and devastation, most residents cannot afford services provided locally. De-localizing these labor costs, in the management team's opinion, was not unethical. With fortyseven people attending the trip and an average workday of approximately 6 hours, the volunteers were able to offset 1,410 hours of charged work to the city of New Orleans and its residents.

The economic impact of a small team of students

DEVASTATION SEEN IN THE LOWER $9^{\mathrm{TH}}$ WARD 
can be surprising. The average value of gutting a house in the New Orleans area is approximately $\$ 10,000$. During our time in New Orleans, the student volunteers were able to gut two houses, keeping in mind that gutting was only one of the services that was provided. In addition to this were the jobs that used unskilled labor, such as debris removal and yard cleaning. At the average hourly rate taken from the U.S. Department of Labor ${ }^{21}$, there was a total of $\$ 7,500$ in unskilled labor performed. As for skilled labor, such as painting and drywall hanging, approximately $\$ 7,200$ worth of work was accomplished. Hence, our collaboration with XULA in this servicelearning engagement contributed approximately $\$ 34,700$ to the New Orleans area.

\section{RECOMMENDATIONS}

By building on the pervious years' clinic service learning experiences and documentation, the management team was able to plan for a successful trip, evaluate the current endeavor, and make recommendations for future Clinic planning when undertaking such an enterprise. The preplanning in the fall semester and the recommendations in previous final reports also supplemented the positive results of the spring break experience. However, it is extremely difficult, perhaps impossible, to plan a trip of this magnitude to absolute perfection. Many issues were encountered by the management team in the areas of preplanning, logistics, and communication. Student availabilities for planning meetings, ground transportation to and from the worksites, and a few miscommunications between the management team and faculty members were some of the issues that impeded decision making and made executing plans challenging. All of these issues were thoroughly examined to provide recommendations for future management teams.

Student leaders planning on organizing a project of this nature would be advised to read the following tips and recommendations so that plans, logistics, and communications remain efficient and healthy:

\section{Preplanning and Logistics}

- Start early! Beginning the search for appropriate projects, accommodations, and contacts too late can lead to a highly unorganized and costly trip. Begin researching target areas and make initial contact with those communities as soon as possible. It is substantially beneficial to form a collaborative relationship with an institution, either academic or industrial, and foster open communication for a joint project.

- Fundraising - Projects of this size can become extremely costly if the team members do not get sponsorship or if the management team does not attempt to gain charitable donations from their university, its associated groups, and multiple businesses.

- Publicity - Get the word out quickly to generate interest among the students and faculty. Good publicity may also lead to successful fundraising.

- Persistence - Maintain scheduled communication between the management team and the contacts for lodging, food, and the projects. Any communication breakdown can lead to confusion and uncertainty when the team arrives.

- Organizing a team - Have regularly scheduled interest meetings without too much immediate detail about the projects. Give general information about how the project works and what has been done before if similar projects have been done. 
- Application/selection process - The management team should also devise an application and selection process for participants based on the diversity recommendation explained in the following bullet point.

- Diversity - One of the key ingredients in making this experience explicitly unique is to have a team composed of different ethnicities, grade levels, skill levels, genders, and cultural backgrounds work as one. A diverse team accomplishing tasks shows that adversities created by all of the aforementioned characteristics can be overcome. This project also gives participants the opportunity to cross-cultural and ethnic boundaries.

\section{Team Meetings}

- Scheduling - Be sure the management team has informative meetings weekly at least 6 weeks prior to the scheduled departure for all of the volunteers who were selected. These meetings are essential in making sure that every team member fulfills their obligations to the project and the necessary paperwork is completed in a timely manner.

- Flexibility - The management team must be able to accommodate the team members' schedules within reason. For example, some commuters may not be able to make night meetings, and other team members may have family responsibilities.

- Reflection - Provide adequate time for reflection before, during, and after the experience. This can be done as a team, individually, or both. The main objective is to get participants to think about what they are doing, what unique challenges are facing them, and chronicle the experience. ${ }^{22}$

\section{Site Logistics}

- Ground transportation - Secure ground transportation for the team members to their worksites every day. Seek the local partner's support for passenger vans, or budget for van rentals and make a schedule for all pickups and drop offs throughout the day.

- Certainty - Know the work that needs to be performed for the next workday. Communicate with work teams about the site location, tools, and materials needed. Verify with your worksite contacts that working plans are firm.

- Do not deviate from logistical plans unless completely necessary! This may cause confusion among the management team, faculty advisors, student volunteers, and local partners.

- Ensure each management team leader knows the locations and schedules of the teams working at other sites. In case of emergencies, changes in personnel, or team site changes, this information is critical for accountability, moving volunteers at a moments notice, and safety concerns. At no time should the management team be without a clear line of communication with other team members.

\section{Work-Related Issues (Ethical Issues, Personnel Issues)}

- Ethical issues - The management team must be prepared to discuss any ethical issues regarding personnel, projects, or management and execution. Ethical issues can arise anytime and must be dealt with professionally. Such "dealings" must take into account issues of race, clan, and gender as well as how engineering projects intersect with these issues. 
- Personnel issues - Subgroups may experience loss of team members due to sickness or other extenuating circumstances. Team replacement plans should be in place in case of those situations.

- Safety equipment - All team members must be properly equipped with any necessary safety gear to reduce the risk of sickness and workplace accidents. Furthermore, volunteers need to bring extra personal medical supplies or prescription drugs in case the trip experiences delays or is prolonged due to weather.

\section{Management Team and Faculty Relations}

- Communication between the management team and faculty leaders is vital to the success of the project. A unified command structure is important; any breakdown in communication is a recipe for disaster. This is best accomplished by having pre-meetings between the management team and faculty supervisors prior to the general team meetings. Ample time must be set aside for these pre-meetings.

\section{Social Activities}

- Make the most of the experience! Although the primary goal is to work and serve the community, it is important for students to engage in social activities to learn more about the culture and history of the communities they are servicing.

- Buddy system - Rely on a buddy system to help increase accountability and safety during free time.

\section{Closing Procedure and Project Fiscal Management}

Project closure is just as important as its preparation. On the trip's completion, any outstanding financial and personal issues need to be addressed. In addition to paying bills, processing appreciation letters and certificates to all involved concluded our administrative and financial close outs. A reception for participants six weeks after the project served as a final reflective session. Before leaving XULA, meetings were arranged with each department with which we conducted business on campus in order to satisfy any outstanding invoices. On departure from Louisiana, all bills were paid and all receipts were in the process of being collected to identify budget issues. Outside of the major expenses such as housing, food, and transportation, other supplies were needed and were addressed accordingly for each specific situation. For example, tools were needed to perform the tasks that were assigned to the student teams. Other unexpected expenses were incurred throughout the week but were still necessary for a successful project. The final portion of the project is to pave way for the next group of student leaders by making available any policies, planning processes, and research concerning the project in a final report. To this end, a detailed project mangers' guide served as a deliverable along with the clinic report at the conclusion of the semester. This operations manual will act as a guide for future trips. It will be composed of do's and do not's, how to's, and contacts that helped with efforts such as finding a supplier for training materials and communicating with the university public relations office.

\section{CONCLUSION}

At the end of the spring break experience, all objectives set forth by the XULA site coordinators were completed via a strong team effort. Of these objectives, the most significant were gutting a complete one-story house and the outside shed, sheet rocking selected bedrooms of a one-story 
house, lawn debris removal from several residences, carpet removal and painting inside another residence, and sanding and painting exterior furniture. Although each of our students and faculty members were volunteers in the relief effort, the trip cost was significant; approximately $\$ 10,000$ was charged to the project account. Despite the costs, the experience gained for each of the students could be considered priceless. The Hurricane Katrina Recovery Team Project demonstrates to all students, not only engineering majors, that real-time issues in our world require technical and social expertise from everyone participating in a project, regardless of their educational background or specializations. Each student had the opportunity to contribute to a large project that affects the lives of many people in a community. Moreover, students also realized that engineering is not just about building bridges or reinforcing the cracks in the pavement; engineering can also mend the lives of those stricken by harsh reality. Project engineering was the biggest part of this endeavor, from scheduling and budgeting all the way through execution and completion. Even though low-skill labor was needed to provide the services, it takes huge efforts in project design to ensure that each of the tasks is completed efficiently and safely. Not only did we get the opportunity to offer a helping hand, we also got the chance to meet local residents and take part in the culturally diverse society that is New Orleans and its surroundings.

Rigorous preplanning in the fall semester and the unending cooperation of all the students and faculty team members made a significantly positive impact on the success of this project. The larger project, with its multiple subprojects, is a means of providing management skills and technical exposure to students in a meaningful way while still being able to service a client. These experiences are measurable components of the accreditation criteria for the university and the general guidelines set forth by the College of Engineering for a Junior/Senior Clinic course. The benefits outlined in this article demonstrate how participants gained meaningful experience and how those in the effected communities experienced both tangible economic benefits and the ability to meet new people willing to help. Perhaps the most important of student benefits was the opportunity to apply management and technical skills in an environment that is constantly changing, which is similar to the work environment. Students were given the opportunity to learn that their skills not only need to be sharp, but also adaptable in real-time situations. The management team also learned how to adapt to the needs of the entire group to accomplish goals quickly and efficiently.

\footnotetext{
${ }^{1}$ The authors wish to express gratitude to many financial contributors, volunteers in New Jersey and New Orleans, the medical and housing staff at Xavier University of Louisiana, the New Orleans field coordinators, Dr. Norman C. Frances, President of Xavier University of Lousiana, and Dr. Donald J. Farish, President of Rowan University and the entire Rowan University community for the many valuable contributions to this endeavour.

2 J. L. Schmalzel et al., "The engineering clinic: A four-year design sequence," $2^{\text {nd }}$ An. NCIIA Nat. Conf., Washington, D.C., 13-15 March 1998.

${ }^{3}$ R. Rmachandran et al., "Integration of Multidisciplinary Design and Technical Communication: An Inexorable Link," International Journal of Engineering Education 18, no. 1 (2002): 32-8.

${ }^{4}$ The clinic's management team is divided into three groups: faculty, a graduate intern, and the senior manager/team leaders. Senior management are students that are seniors and have project management experience; team leaders are junior engineering students enrolled in the clinic "class."

${ }_{5}^{5}$ J. M. Nicholas, Project Management for Business and Technology: Principles and Practice (Upper Saddle River, NJ: Prentice Hall, 2001), 22-3.

${ }^{6}$ Students engaged in Rebuilding America: A toolkit for organizing group service trips to the Gulf Coast to help communities recover from the Hurricanes of 2005. (The Corporation for National and Community Service and the U.S. Department of Housing and Urban Development. August 2006.)
} 
${ }^{7}$ Accreditation Board for Engineering and Technology (ABET), "Criteria for Accrediting Engineering Programs," The Engineering Accrediting Commission of the Accreditation Board for Engineering and Technology, (2000), Retrieved May 1, 2007. http://www.abet.org/eac/eac.htm. See also ABET, "Engineering Criteria 2002-2003," Accreditation Board for Engineering and Technology, (2002), http://www.abet.org/criteria.htm. And Jennifer Kadlowec et al., "Katrina Recovery Clinic Project: An Engineering Service Leasing Experience." Presented at the $36^{\text {th }}$ ASEE/IEEE Frontiers in Education Conference, San Diego, CA, October 28-31, 2006.

${ }^{8}$ B. Jacoby et al., Service Learning in Higher Education (San Francisco, CA: Jossey-Bass, 1996), 5.

${ }^{9}$ Y. Metha and Beena Sukumaran, "Integrating Service Learning in Engineering Clinics," International Journal of Service Learning In Engineering 2, no. 1 (2007): 32-43.

10 Donna Riley and Alan Bloomgarden, "Learning and Service in Engineering and Global Development," International Journal for Service Learning in Engineering 2, no. 1 (2006): 48-59.

${ }^{11}$ The group activities included a walk in the Lower Ninth Ward, which is the location where the levy broke, a tour of the Historic French Quarter, a question and answer session along the levy, a visit to a local church, and trips to the Cabildo and Presbyter museums in New Orleans. These activities exposed the student volunteers to a different culture and allowed them to learn about the effect of the natural disaster on the community and people of New Orleans.

${ }^{12}$ J. Eyler and D. E. Giles Jr., Where's the Learning in Service-Learning? (San Francisco, CA: Jossey-Bass, 1999).

${ }^{13}$ R. C. Niemi \& Associates, The Politics of Future Citizens (San Francisco, CA: Jossey-Bass, 1974).

${ }^{14}$ Eyler and Giles, Where's the learning in service-learning?

${ }^{15}$ T. Williamson, "Work-Based Learning: A Leadership Development Example from an Action Research Study of Shared Governance Implementation," Journal of Nursing Management 13 (2005): 490-9.

${ }^{16}$ Nicholas, Project Management for Business and Technology: Principles and Practices, 22-3.

${ }^{17}$ Nicholas, Project Management for Business and Technology: Principles and Practices, 22-3.

${ }^{18}$ Karol K. Weaver, "Integrating Service Learning into a History of Feminist Theory Course," Transformations: The Journal of Inclusive Scholarship and Pedagogy 14 (2003): 45-62.

19 Beverly A. Peterson et al., "Service-Learning Projects Meeting Community Needs," Home Health Care Management \& Practice 18, no. 4 (2006): 315-22.

${ }^{20}$ Peterson et al., "Service-Learning Projects Meeting Community Needs," 315-22.

${ }^{21}$ These estimates are based on The U.S. Department of Labor website. Retrieved August 1, 2007. http://www.dol.gov/dolfaq/go-dol-

faq.asp? faqid $=359 \&$ faqsub $=$ General $\&$ faqtop $=$ Grants $+\% 26+$ Contracts $\&$ topicid $=15$.

${ }^{22}$ Jennifer Kadlowec et al., "Katrina Recovery Clinic Project." 